\title{
Stochastic renewable energy resources integrated multi-objective optimal power flow
}

\author{
Sundaram B. Pandya, Hitesh R. Jariwala
}

Department of Electrical Engineering, S. V. National Institute of Technology, India

\begin{tabular}{l}
\hline \hline Article Info \\
\hline Article history: \\
Received Jul 2, 2019 \\
Revised Jan 30, 2020 \\
Accepted Feb 26, 2020 \\
\hline
\end{tabular}

\section{Keywords:}

Meta-heuristics

Probability density function

Solar PV energy

Stochastic

Wind units

\begin{abstract}
The modern state of electrical system consists the conventional generating units along with the sources of renewable energy. The proposed article recommends a method for the solution of single and multi-objective optimal power flow, integrating wind and solar output energy with traditional coal-based generating stations. In the first part of the article, the two wind power plants and one solar PV power plants are incorporated with the thermal power plants. The optimal power flow problem of single and conflicting multi-objectives are taken with this scenario. The second part of the paper, solar power plant is replaced with another wind power plant with the conventional coal-based power plants. The techno-economic analysis are done with this state of electrical system. In proposed work, lognormal and weibull probability distribution functions are also utilized for predicting solar and wind outputs, respectively. A non-dominated multi-objective moth flame optimization technique is used for the optimization issue. The fuzzy decision-making approach is applied for extracting the best compromise solution. The results are validated though adapted IEEE-30 bus test system, which is incorporated with wind and solar generating plants.
\end{abstract}

This is an open access article under the CC BY-SA license.

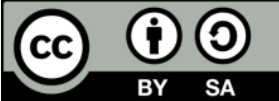

\section{Corresponding Author:}

Sundaram B. Pandya,

Department of Electrical Engineering,

S. V. National Institute of Technology, Surat, India.

Email: sundarampandya@gmail.com

\begin{tabular}{ll} 
LIST OF NOMENCLATURE \\
\hline OPF & Optimal Power Flow \\
TG & Thermal Generator \\
WG & Wind Generator \\
PV & Photo Voltaic \\
ISO & Independent System Operator \\
PDF & Probability Density Function \\
BCS & Best Compromise Solution \\
MOMFO & Multi-Objective Moth Flame Optimization \\
MOOPF & Multi-Objective Optimal Power Flow \\
$P_{T G i}$ & Power output of $i^{t h}$ thermal unit. \\
$P_{w s, j}$ & Scheduled power from $j^{t h}$ wind power unit \\
$P_{s s, k}$ & Scheduled power from $k^{t h}$ solar PV unit \\
$P_{w a v, j}$ & Actual available power from $j^{t h}$ wind power unit \\
$P_{s a v, k}$ & Actual available power from $k^{t h}$ solar PV unit \\
$g_{j}$ & Direct cost coefficient for $j^{t h}$ wind power unit
\end{tabular}




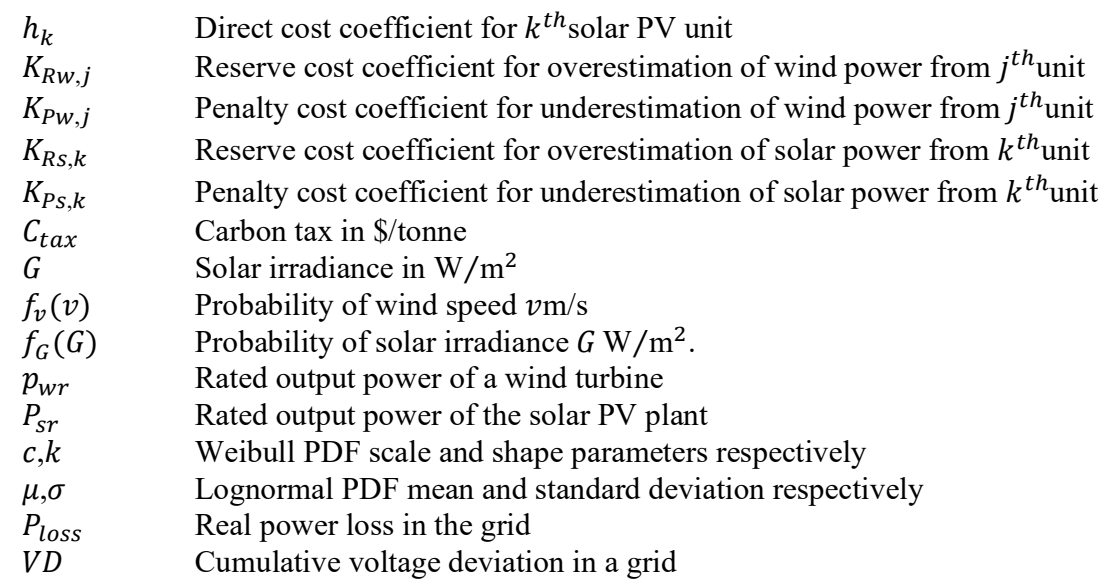

\section{INTRODUCTION}

The optimal power flow (OPF) play a vital role in obtaining regulation and operational management of the electrical grid. The root focus of OPF is to find out the operational region of the electrical network by optimizing the certain objective along with non-violating equality and inequality bounds. It was first introduced by Carpentier [1]. Last few years, many stochastic techniques have been proposed in [2-12] for the OPF problem.

While above-mentioned citations consider only classical generating units. An electrical system comprising wind and thermal power units has currently been considered in search of optimum generating cost in some of the articles. Gbest directed artificial bee colony (GABC) is put in used in [13] for the enhancement of OPF outputs obtained in earlier articles using same experimental arrangement. In [14] introduced a modified bacteria foraging approach (MBFA) and proposed a doubly fed induction generator (DFIG) structure in the OPF agenda to express bounds on VAR power production capacity. Another VAR power compensating device, static synchronous compensator (STATCOM) is integrating with [15] for a network having thermal and wind units. Also, the OPF issue was solved with the help of ant colony optimization (ACO) as well as MBFA. Shi et al. [16] introduced a pattern for the formulation of the cost of wind power. Generators scheduling problem for economic dispatch is a usual problem for a utility having wind power and thermal units. Jabr and Pal [17] offered a stochastic model of wind power production. In additional, while solving the similar issue, Mishra et al. [18] involved DFIG model of wind turbine. Wei at al. [19] introduced dynamic economic dispatch (DED) structure comprising a wide range of wind energy with risk reserve limits. Dubey [20] included valve-point loading effect of generating unit and emission in DED structure. OPF scheduling system for a solitary hybrid network having solar PV, battery and the diesel generating unit is explained in [21]. Pumped hydro storage is presented in [22] as a substitute storage for the same standalone hybrid network comprising of a wind generating unit, a solar PV, and a diesel generating unit.

Now a days, the major challenge in power system is an integrating the renewable energy sources like wind and solar PV power in power grid. The single and multi-objective optimal power flow including with the renewable energy sources focused the maximum attention. The author's influence in this paper, are as follows:

- This article is devoted to the mathematical modeling of the single and multi-objective OPF problems including complete uncertainty modeling of thermal plants, wind power plants and solar PV power plant in the first part.

- Calculations and modeling of the different probability density functions comprising the stochastic wind and solar power plants.

- In second part solar power plant is replaced with the wind power plant and finally find out the solution of single and multi-objective OPF problem with the comparative techno-economic analysis.

- The non-dominated sorting Moth Flame Optimization technique is applied for finding solutions of single and multi-objective OPF problems including stochastic renewable energy sources like wind and solar PV power.

The further sections of the article are arranged as: section 2 consist of the analysis of mathematical models containing a formulation of uncertainties in solar and wind energy outcomes regarding OPF problem. Section 3 includes discussion on the objectives which is to be optimized. Explanation and application of multi-objective MFO approach are explained in section 4. Numerical results and discussion are presented in section 5 and conclusive notes given in section 6 .

\section{MATHEMATICAL MODELS}

The elementary information data of modified IEEE-30 bus power system considering the thermal power plants and renewable resources is shown in Table 1. The bus number 5, bus number 11 and bus number 
13 are replaced with the renewable sources. All the thermal plants, wind and solar plants contribute to the total cost of generation. The cost of the conventional thermal generating plants and the renewable sources plants are described in the below section.

Table 1. The main characteristics of the system under study

\begin{tabular}{lcc}
\hline \multicolumn{1}{c}{ Items } & Quantity & Details \\
\hline Buses & 30 & {$[23]$} \\
Branches & 41 & {$[23]$} \\
Thermal generators (TG1; TG2; TG3) & 3 & Buses: 1 (swing), 2 and 8 \\
Wind generators (WG1; WG2) & 2 & Buses: 5 and 11 \\
Solar PV unit (SPV) or Wind generator (WG3) & 1 & Bus: 13 \\
Control variables & 24 & - \\
Connected load & - & $283.4 \mathrm{MW}, 126.2 \mathrm{MVAr}$ \\
\hline
\end{tabular}

\subsection{Cost of thermal power units}

The thermal generating units operating with the fossil fuels and non-convexity containing numerous swells because of the existence of stacking impacts of the valve point. The ripple effect upon the cost curve is included as redressing sinusoids with quadratic costs. Scientifically, the cost in $\$ / \mathrm{hr}$ having a valve-point effect is treated as:

$$
C_{T}\left(P_{T G}\right)=\sum_{i=1}^{N_{T G}} a_{i}+b_{i} P_{T G i}+c_{i} P_{T G i}^{2}+\left|d_{i} \times \sin \left(e_{i} \times\left(P_{T G i}^{\min }-P_{T G i}\right)\right)\right|
$$

where $a_{i}, b_{i}$ and $c_{i}$ are the cost coefficients for $i^{t h}$ thermal power plant. Also $e_{i}$ and $d_{i}$ are the cost coefficients because of valve point effect.

\subsection{Emission}

The non-renewable energy sources release toxic gases in the atmosphere during power generation. The discharge of NOx and Sox rises with an increase in thermal plants outputs as indicated in (2). Emission in tones per hour (ton/hr) can be determined as:

$$
\text { Emission } E=\sum_{i=1}^{N_{T G}}\left[\left(\alpha_{i}+\beta_{i} P_{T G i}+\gamma_{i} P_{T G i}^{2}\right) \times 0.01+\omega_{i} e^{\left(\mu_{i} P_{T G i}\right)}\right]
$$

where, $\alpha_{i}, \beta_{i}, \gamma_{i}, \omega_{i}$ and $\mu_{i}$ are the emission coefficients with respect to the $i^{\text {th }}$ thermal unit. The values of thermal cost coefficients and emission coefficients of thermal power plants are displayed in Table 2 .

Table 2. Cost coefficients and emission coefficients of the system under study

\begin{tabular}{ccccccccccccc}
\hline Generator & Bus & $a$ & $b$ & $c$ & $d$ & $e$ & $\alpha$ & $\beta$ & $\gamma$ & $\omega$ \\
\hline$T G 1$ & 1 & 0 & 2 & 0.00375 & 18 & 0.037 & 4.091 & -5.554 & 6.49 & 0.0002 & 6.667 \\
$T G 2$ & 2 & 0 & 1.75 & 0.0175 & 16 & 0.038 & 2.543 & -6.047 & 5.638 & 0.0005 & 3.333 \\
$T G 3$ & 8 & 0 & 3.25 & 0.00834 & 12 & 0.045 & 5.326 & -3.55 & 3.38 & 0.002 & 2 \\
\hline
\end{tabular}

\subsection{Direct cost of stochastic renewable plants}

The renewable sources are stochastic in nature and it is very difficult to integrate these sources into the power grid. The wind and solar power units are controlled through the independent system operator (ISO). So the private operator has to make the agreement with the grid for a certain amount of scheduled power. The ISO must be sustained the scheduled power. If these renewable farms are not able to maintain the scheduled power, ISO is responsible for the deficiency of the power. So the spinning reserve supplies the power, if power demand arise. This spinning reserve adds extra cost for the ISO and this condition is termed as overestimation of the renewable sources like wind and solar PV farms. Similarly, in opposite way, if these renewable sources produced more power compared to the scheduled power, it can be wasted because of non-utilization. So the ISO must tolerate the penalty charge. Thus, the direct cost of the non-conventional units allied with the scheduled power, overestimation cost because of the spinning reserve and the penalty cost because of the underestimation.

Direct cost related to the wind farms from the $j^{\text {th }}$ power plant is modeled with the $P_{w s, j}$ scheduled power from the same sources as:

$$
C_{w, j}\left(P_{w s, j}\right)=g_{j} P_{w s, j}
$$

where $g_{j}$ indicate the direct cost coefficient and $P_{w s, j}$ is treated as the scheduled power of the $j^{\text {th }}$ power plant. 
Similarly, the direct cost related to the solar PV farms from $k^{\text {th }}$ power plant is demonstrated with the $P_{s s, k}$ scheduled power from the same sources as:

$$
C_{s, k}\left(P_{s s, k}\right)=h_{k} P_{s s, k}
$$

where $h_{k}$ indicates the direct cost coefficient and $P_{s s, k}$ is treated as the scheduled power of the $k^{\text {th }}$ power plant.

\subsection{Uncertain renewable wind power cost}

Owing to the uncertainty of the wind, occasionally the wind farm produces the less amount of the power as compared to scheduled power. Sometimes, it may be possible that actual power provided by wind farm may not be satisfying the demand and have lower values. Such power is known as overestimated power by an indeterminate resource. The network ISO should require a spinning reserve to cope up with this type of uncertainty and deliver continuous power source to the end users. The cost of obligating a reserve generator to fulfill the overestimated power is named as reserve cost. Reserve cost for the $j^{\text {th }}$ wind unit is formulated by:

$$
\begin{aligned}
C_{R w, j}\left(P_{w s, j}-P_{w a v, j}\right) & =K_{R w, j}\left(P_{w s, j}-P_{w a v, j}\right) \\
& =K_{R w, j} \int_{0}^{P_{w s, j}}\left(P_{w s, j}-p_{w, j}\right) f_{w}\left(p_{w, j}\right) d p_{w, j}
\end{aligned}
$$

where, $K_{R w, j}$ represents a reserve cost coefficient regarding $j^{\text {th }}$ wind unit, $P_{w s, j}$ is the definite accessible power from the same unit. $f_{w}\left(p_{w, j}\right)$ represents the wind power probability density function for $j^{\text {th }}$ wind unit.

Opposite to the overestimation condition, it may be possible that the actual power provided by the wind farm is higher from the demand value. Such a scenario is called underestimated power. The leftover power will be lost if there is not any provision for controlling the output power from thermal units. ISO should be paid a penalty charge regarding the excess power. Penalty charge for the $j^{t h}$ wind unit is given by:

$$
\begin{aligned}
C_{P w, j}\left(P_{w a v, j}-P_{w s, j}\right) & =K_{P w, j}\left(P_{w a v, j}-P_{w s, j}\right) \\
& =K_{P w, j} \int_{P_{w s, j}}^{P_{w r, j}}\left(p_{w, j}-P_{w s, j}\right) f_{w}\left(p_{w, j}\right) d p_{w, j}
\end{aligned}
$$

where, $K_{P w, j}$ represents a penalty cost coefficient of $j^{t h}$ wind unit, $P_{w r, j}$ gives the specified output power of the same unit.

\subsection{Uncertain renewable solar $P V$ power cost}

Solar PV unit also has an irregular and uncertain generation. In fact, the tactic for underestimation and overestimation of solar power will be similar to the case of wind power. Though, radiation of solar trails lognormal PDF [23], unlike as of wind power supply that is popular for trailing Weibull PDF, for ease in computation, a penalty as well as reserve cost structures were made according to the idea explained in [23]. Reserve cost of $k^{\text {th }}$ solar PV unit can be written as:

$$
\begin{aligned}
C_{R s, k}\left(P_{s s, k}-P_{s a v, k}\right) & =K_{R s, k}\left(P_{s s, k}-P_{s a v, k}\right) \\
& =K_{R s, k} * f_{s}\left(P_{s a v, k}<P_{s s, k}\right) *\left[P_{s s, k}-E\left(P_{s a v, k}<P_{s s, k}\right)\right]
\end{aligned}
$$

where $K_{R s, k}$ is the reserve cost coefficient regarding $k^{\text {th }}$ solar PV unit, $P_{s a v, k}$ is the definite accessible power from the same unit. $f_{s}\left(P_{s a v, k}<P_{s s, k}\right)$ shows the possibility of solar output power deficiency incidence with respect to scheduled output power $\left(P_{s s, k}\right), E\left(P_{s a v, k}<P_{s s, k}\right)$ shows the anticipation to the solar PV output power lower than $P_{s s, k}$.

Penalty cost of under-estimation of $k^{t h}$ solar PV unit can be given by:

$$
\begin{aligned}
C_{P S, k}\left(P_{s a v, k}-P_{s s, k}\right) & =K_{P s, k}\left(P_{s a v, k}-P_{s s, k}\right) \\
& =K_{P S, k} * f_{s}\left(P_{s a v, k}>P_{s s, k}\right) *\left[E\left(P_{s a v, k}>P_{s s, k}\right)-P_{s s, k}\right]
\end{aligned}
$$

where $K_{P s, k}$ represents the coefficient of penalty cost regarding $k^{\text {th }}$ solar PV unit, $f_{s}\left(P_{s a v, k}>P_{s s, k}\right)$ shows the possibility of solar output in excess with respect to the scheduled output power $\left(P_{s s, k}\right), E\left(P_{s a v, k}>P_{s s, k}\right)$ shows the anticipation of solar $\mathrm{PV}$ output power higher than $P_{s s, k}$.

\subsection{Uncertainty models of stochastic wind/solar power}

In adapted IEEE-30 bus case study, the thermal generating units which are located at bus- 5 and bus- 11 , replaced by wind power generating units. Data of proposed Weibull shape $(k)$ and scale $(c)$ parameters were 
displayed in Table 3. Weibull fitting and wind frequency distributions in Figures 1 (a) and 1 (b) are achieved by taking 8000 Monte-Carlo scenarios. The Standard given in [23] instructs the design necessity of wind turbines and states maximum turbulent class IA that is verified to operate at highest yearly average wind velocity of 10 meters/sec at hub height. Special focus is for taking shape $(k)$ and scale $(c)$ parameters of wind farms as highest Weibull PDF mean value stuck near 10. In addition, various PDF parameters for two wind farms depict the accurate topographical variety of locations. This is very well known that the distribution of wind speed tracks Weibull probability density function (PDF).

Table 3. PDF parameters of wind and solar PV plants

\begin{tabular}{|c|c|c|c|c|c|c|c|}
\hline \multicolumn{5}{|c|}{ Wind power generating plants } & \multicolumn{3}{|c|}{ Solar PV plant } \\
\hline $\begin{array}{l}\text { Wind } \\
\text { farm\# }\end{array}$ & $\begin{array}{l}\text { No. of } \\
\text { turbines }\end{array}$ & $\begin{array}{c}\text { Rated power, } \\
P_{w r}(\mathrm{MW})\end{array}$ & $\begin{array}{l}\text { Weibull PDF } \\
\text { parameters }\end{array}$ & $\begin{array}{l}\text { Weibull mean, } \\
\qquad M_{w b l}\end{array}$ & $\begin{array}{c}\text { Rated power, } \\
P_{s r}(\mathrm{MW})\end{array}$ & $\begin{array}{l}\text { Lognormal PDF } \\
\text { parameters }\end{array}$ & $\begin{array}{l}\text { Lognormal } \\
\text { mean, } M_{l g n}\end{array}$ \\
\hline 1 (bus 5) & 25 & 75 & $c=9, k=2$ & $v=7.976 \mathrm{~m} / \mathrm{s}$ & 50 (bus 13) & $\mu=6, \sigma=0.6$ & $G=483 \mathrm{~W} / \mathrm{m}^{2}$ \\
\hline 2 (bus 11$)$ & 20 & 60 & $c=10, k=2$ & $v=8.862 \mathrm{~m} / \mathrm{s}$ & & OR & \\
\hline 3 (bus 13) & 17 & 51 & $c=9, k=2$ & $v=7.976 \mathrm{~m} / \mathrm{s}$ & Wind power & enerating plant at $\mathrm{I}$ & Is-13 (Part-2) \\
\hline
\end{tabular}

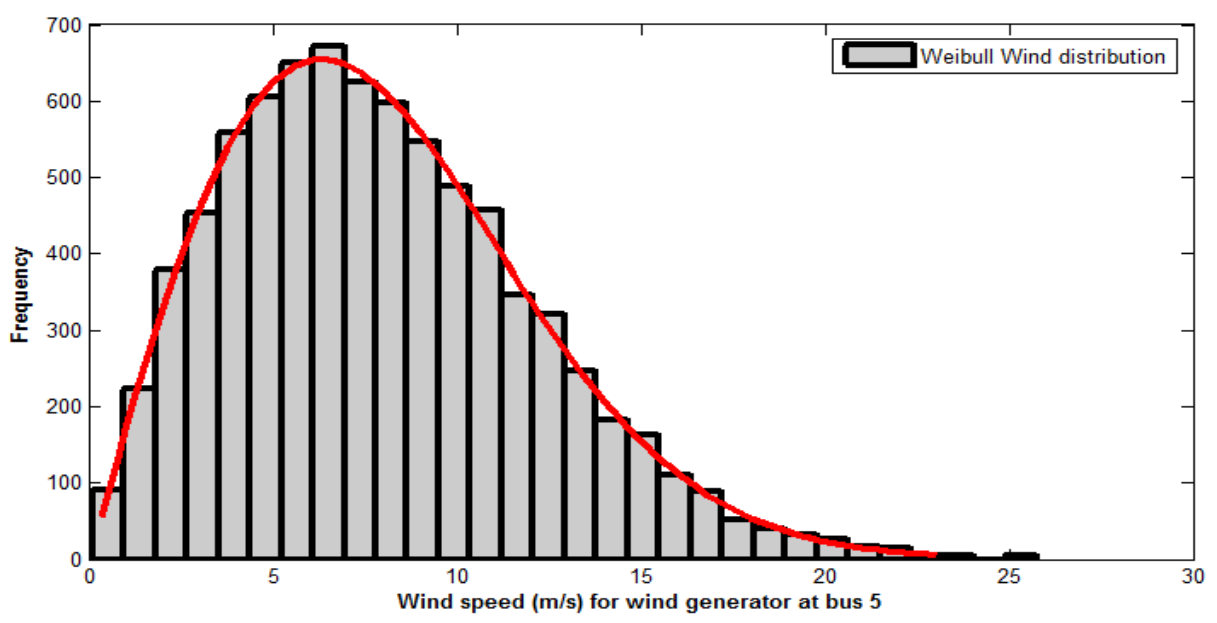

(a)

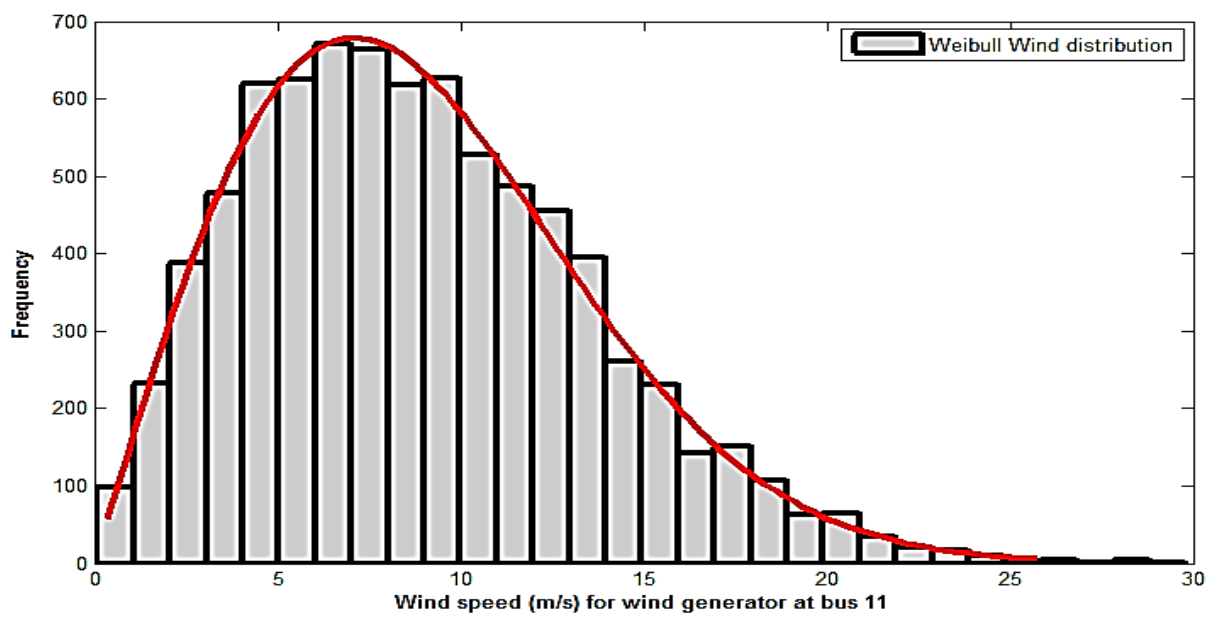

(b)

Figure 1. Weibull PDF for wind farm located at (a) Bus-5, (b) Bus-11

The possibility of wind velocityvmeter/sec pursuing Weibull PDF including shape factor $(k)$ and scale factor $(c)$ can be calculated as:

$$
f_{v}(v)=\left(\frac{k}{c}\right)\left(\frac{v}{c}\right)^{(k-1)} e^{-\left(\frac{v}{c}\right)^{k}} \quad \text { for } 0<v<\infty
$$


mean of Weibull distribution is stated as:

$$
M_{w b l}=c * \Gamma\left(1+k^{-1}\right)
$$

where gamma function $\Gamma(x)$ is given by:

$$
\Gamma(x)=\int_{0}^{\infty} e^{-t} t^{x-1} d t
$$

Thermal unit coupled to bus number-13 of IEEE-30 bus network is substituted with the solar plant. The generation by the source is reliant on solar irradiance $(G)$ that tracks lognormal PDF [23]. The possibility of the solar irradiance $(G)$ pursuing lognormal PDF having mean $\mu$ and standard deviation $\sigma$ can be given as:

$$
f_{G}(G)=\frac{1}{G \sigma \sqrt{2 \pi}} \exp \left\{\frac{-(\ln x-\mu)^{2}}{2 \sigma^{2}}\right\} \quad \text { for } G>0
$$

mean of lognormal distribution can be given by:

$$
M_{l g n}=\exp \left(\mu+\sigma^{2} / 2\right)
$$

Figure 2 specifies a distribution of frequency and lognormal fitting of solar irradiance by simulating the Monte Carlo scenario, taking reference value of 8000. Table 3 states the nominated Weibull and lognormal PDF parameters. For wind and solar PV power see in the [23].

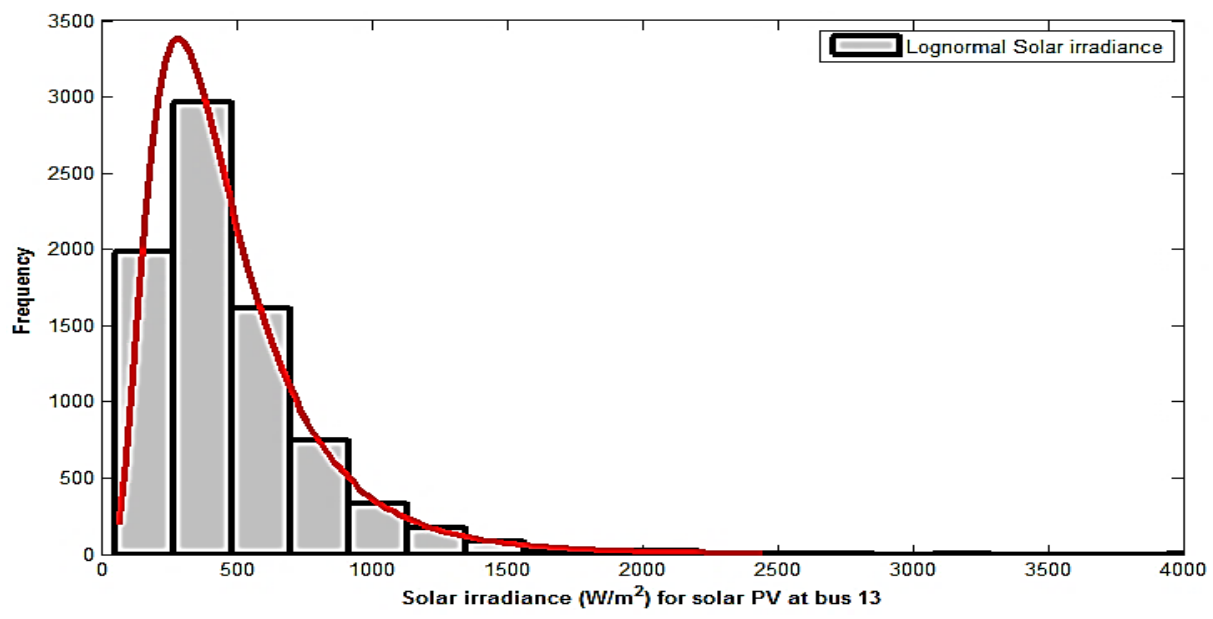

Figure 2. Lognormal PDF for the solar plant located at bus-13

\section{OBJECTIVES OF OPTIMIZATION}

The optimal power flow contains the objectives of optimal active power dispatch and optimal reactive power dispatch. In this section, the objectives of optimal power flow with wind and solar power plants are incorporated as follows;

\subsection{Minimization of total fuel cost including renewable energy resources}

The OPF objective is modeled by integrating every cost function that are discussed earlier. In the first objective, the cost of wind and solar power plants are added to the conventional thermal power plants. While, emission cost is not considered. Next objective function is formulated by including emission cost to analyze the change in generation schedule at the time of imposition carbon tax.

Objective 1: Minimize-

$$
\begin{aligned}
& F_{1}=C_{T}\left(P_{T G}\right)+\sum_{j=1}^{N_{W G}}\left[C_{w, j}\left(P_{w s, j}\right)+C_{R w, j}\left(P_{w s, j}-P_{w a v, j}\right)+C_{P w, j}\left(P_{w a v, j}-\right.\right. \\
& \left.\left.P_{w s, j}\right)\right]+\sum_{k=1}^{N_{S G}}\left[C_{s, k}\left(P_{s s, k}\right)+C_{R s, k}\left(P_{s s, k}-P_{s a v, k}\right)+C_{P s, k}\left(P_{s a v, k}-P_{s s, k}\right)\right]
\end{aligned}
$$


where $N_{W G}$ and $N_{S G}$ represent the no. of wind units and solar PV units in a grid, respectively. Remaining cost parameters are determined from (1) and (3) to (8).

\subsection{Minimization of total fuel cost plus carbon Emission tax including renewable energy resources}

Nowadays, some of the countries are pressurizing the whole power utility to diminish the carbon discharge to control the global warming [23]. In order to inspire venture in cleaner ways of power such as solar and wind, carbon tax $\left(C_{\text {tax }}\right)$ is charged on discharged of per unit greenhouse smokes. The emission cost (in $\$ / \mathrm{hr}$ ) is denoted by (2): Emission cost, $C_{E}=C_{\text {tax }} E$

Objective 2: minimize -

$$
F_{2}=F_{1}+C_{\text {tax }} E
$$

\subsection{Minimization of voltage deviation with renewable energy resources}

Bus voltage is a standout among the highest imperative safety and administration superiority lists. The enhancing voltage profile will be acquired by limiting the deviations in voltage of PQ bus from 1.0 for every unit. The objective function will be given by;

Objective 3: minimize -

$$
F 3=\sum_{i=1}^{N_{p q}}\left|v_{i}-1.0\right|
$$

where $N_{p q}$ shows the no. of load (PQ) buses, $v_{i}$ shows the p.u. the voltage level of $i^{\text {th }}$ bus.

\subsection{Minimization of active power losses with renewable energy resources}

The optimization of real power losses $P_{\text {LOSS }}$ (MW) may be computed by; Objective 4: minimize -

$$
F 4=P_{L O S S}=\sum_{i=1}^{N B} P_{G i}-\sum_{i=1}^{N B} P_{D i}
$$

where $P_{G i}$ and $P_{D i}$ represent the output and dispatch at $i^{\text {th }}$ bus; $N B$ shows the number of buses.

\subsection{Enhancement of voltage stability index containing renewable energy resources}

The most significant index, which indicates the voltage constancy margin of each bus, is the $L_{\max }$ index to preserve the constant voltage within suitable level under normal operating conditions. L-index provides a scalar number for every PQ bus. $L_{\max }$ index lies in a span of '0' (no load) and '1' (voltage collapse). The amount of voltage collapse indicator for $j^{\text {th }}$ bus is obtained as:

$$
\begin{aligned}
L_{j} & =\left|1-\sum_{i=1}^{N_{g}} F_{j i} \frac{V_{i}}{V_{j}}\right| \quad \forall j=1,2, \ldots \ldots, N L \\
F_{j i} & =-\left[Y_{1}\right]^{-1}\left[Y_{2}\right]
\end{aligned}
$$

where $Y_{1}$ and $Y_{2}$ were the sub-matrices of $Y_{B U S}$. The objective function of voltage stability enhancement is written by:

$$
F 5=L=\max \left(L_{j}\right) \quad \forall j=1,2, \ldots \ldots, N L
$$

\subsection{Equality constraints}

Equality bounds are given by power flow equations which shows that both real and imaginary power produced in a system should have satisfied the load demand and losses in the system.

$$
\begin{aligned}
& P_{G i}-P_{D i}-V_{i} \sum_{j=1}^{N B} V_{j}\left[G_{i j} \cos \left(\delta_{i j}\right)+B_{i j} \sin \left(\delta_{i j}\right)\right]=0 \forall i \in N B \\
& Q_{G i}-Q_{D i}-V_{i} \sum_{j=1}^{N B} V_{j}\left[G_{i j} \sin \left(\delta_{i j}\right)-B_{i j} \cos \left(\delta_{i j}\right)\right]=0 \forall i \in N B
\end{aligned}
$$

where $\delta_{i j}=\delta_{i}-\delta_{j}$, is the variance in phase angles of voltage among busiand bus $j, N B$ shows overall buses, $P_{D i}$ and $Q_{D i}$ are real and VAR power demand respectively at $i^{\text {th }}$ bus. $P_{G i}$ and $Q_{G i}$ are real and VAR 
outputs respectively of $i^{\text {th }}$ busby either unit (thermal or non-conventional) as applicable. $G_{i j}$ shows the conductance and $B_{i j}$ shows the susceptance between bus $j$ and bus $i$, respectively.

\subsection{Inequality constraints}

Inequality bounds were the operational boundaries of devices and security bounds of lines and PQ buses. In (23) to (25) signifies the real power output bounds of thermal, wind units and solar units respectively. Afterward, (26) to (28) signifies the VAR power capacity of generating units. $N G$ shows the overall voltage control buses. In (29) shows bounds on the voltage of PV buses, whereas, (30) shows the voltage bounds on PQ buses where $N L$ is the number of PQ buses. Line loading boundaries are defined using (31) for total $n l$ number of lines in a system.

$$
\begin{aligned}
& \text { Generator bounds: } P_{T G i}^{\min } \leqslant P_{T G i} \leqslant P_{T G i}^{\max }, i=1, \ldots \ldots, N_{T G} \\
& P_{w s, j}^{\min } \leqslant P_{w s, j} \leqslant P_{w s, j}^{\max }, j=1, \ldots . ., N_{W G} \\
& P_{s s, k}^{\min } \leqslant P_{s s, k} \leqslant P_{s s, k}^{\max }, k=1, \ldots ., N_{S G} \\
& Q_{T G i}^{\min } \leqslant Q_{T G i} \leqslant Q_{T G i}^{\max }, i=1, \ldots ., N_{T G} \\
& Q_{w s, j}^{\min } \leqslant Q_{w s, j} \leqslant Q_{w s, j}^{\max }, j=1, \ldots \ldots, N_{W G} \\
& Q_{S S, k}^{\min } \leqslant Q_{s s, k} \leqslant Q_{S S, k}^{\max }, k=1, \ldots \ldots, N_{S G} \\
& V_{G i}^{\min } \leqslant V_{G i} \leqslant V_{G i}^{\max }, i=1, \ldots ., N G \\
& \text { Security bounds. } V_{L_{p}}^{\min } \leqslant V_{L_{p}} \leqslant V_{L_{p}}^{\max }, p=1, \ldots \ldots, N L \\
& S_{l_{q}} \leqslant S_{l_{q}}^{\max }, q=1, \ldots \ldots, n l
\end{aligned}
$$

\section{MULTI-OBJECTIVE MOTH FLAME OPTIMIZER}

Here, the Moth Flame Optimization (MFO) algorithm is adopted to solve the multi-objective optimal power flow problem.

\subsection{Inspiration}

It is basically inspired from the moths in nature. The navigation of the moths at night is a little bit interesting by using the moonlight. The transverse orientation of mechanism is utilized by the moths for navigation as shown in Figure 3. The moth flies by keeping up some point concerning the moon, the vital and viable mechanics of long traveling long separations. Be that as it may, regardless of the transverse orientation, moths fly spirally around the lights. This is a direct result of the inadequacy of the transverse introduction, in which it is valuable for suffering in a linear way at the time of remote location light source. Exactly when moths get an artificial light source, they do efforts to keep up a comparative edge to a light source to soar in a linear way. Meanwhile, this light is to an extraordinary degree close stood out from the moon, nevertheless, keeping up the same point at a light source creates a vain or lethal winding to sail route for moths.
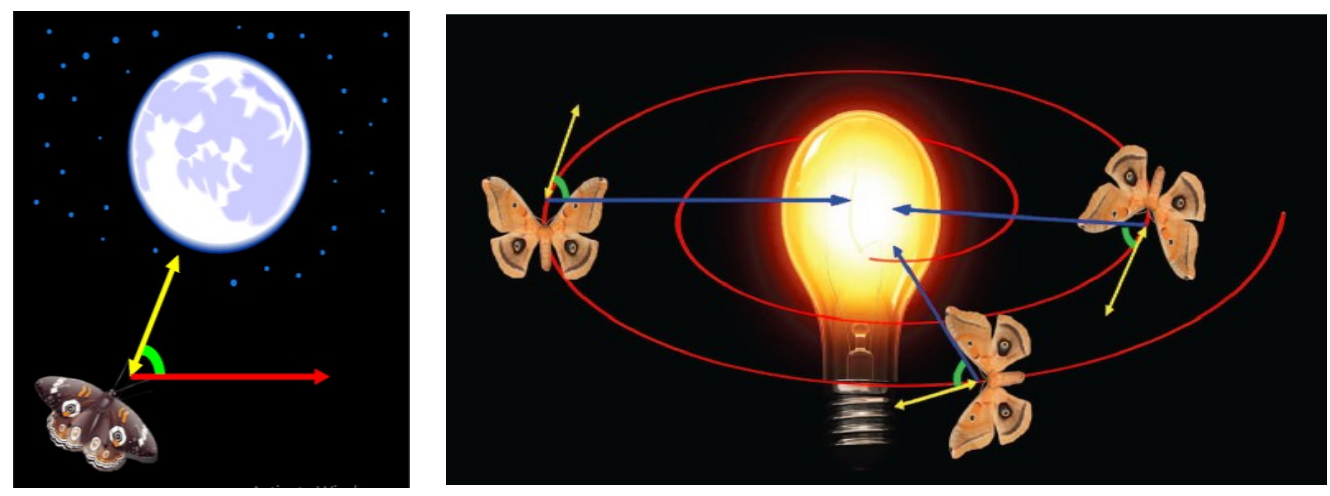

Figure 3. Transverse orientation [24] 


\subsection{MFO algorithm}

In MFO algorithm, the solutions of problems are given by moths and the variables are represented by the positions of moths in a space, flying in 1D, 2D, 3D or any other dimensional space by varying its position vectors. a. Initialize position vector of moths

With ' $n$ ' shows the overall variables and' $d$ ' shows the dimensions, the position matrix is given by;

$$
M=\left[\begin{array}{cccc}
m_{1,1} & m_{1,2} & \cdots & m_{1, d} \\
m_{2,1} & m_{2,2} & \cdots & m_{2, d} \\
\vdots & \vdots & \vdots & \vdots \\
m_{n, 1} & m_{1,1} & \cdots & m_{n, d}
\end{array}\right]
$$

b. Initialize position vector of flames

Another valuable matrix is the position vector matrix of flames which is given by;

$$
F=\left[\begin{array}{cccc}
F_{1,1} & F_{1,2} & \cdots & F_{1, d} \\
F_{2,1} & F_{2,2} & \cdots & F_{2, d} \\
\vdots & \vdots & \vdots & \vdots \\
F_{n, 1} & F_{1,1} & \cdots & F_{n, d}
\end{array}\right]
$$

where the ' $n$ ' shows overall variables and the ' $d$ ' shows overall dimensions.

c. Fitness evaluation

For the finding the fitness there is an array of the moths which is given by:

$$
O M=\left[\begin{array}{c}
O M_{1} \\
O M_{2} \\
\vdots \\
O M_{n}
\end{array}\right]
$$

where ' $n$ ' gives the overall value of moths. It may be seen that the dimensions of the position vectors of moths and flames are the same. So the vector for saving the equivalent fitness value is given by:

$$
O F=\left[\begin{array}{c}
O F_{1} \\
O F_{2} \\
\vdots \\
O F_{n}
\end{array}\right]
$$

The MFO approach is having the three main functions for finding the global results as:

$$
M F O=(I, P, T)
$$

I show the function for generating the custom populations with the corresponding fitness which is given by:

$$
I: \emptyset \rightarrow\{M, O M\}
$$

similarly, $P$ function is also the main function, and getting from the matrix of $M$ eventually updated as:

$$
P: M \rightarrow M
$$

also, there is another termination criterion for $T$ function for the condition, satisfaction means if satisfied than true otherwise false.

$$
: M \rightarrow\{T R U E, F A L S E\}
$$

Firstly, the initialization of the functions, the ' $P$ ' function is evaluated until the satisfaction standards of the ' $T$ ' function are not fulfilled. Now the moth is modified according to the flame, so the mathematical model of the transverse orientations of this behavior is given by the equation given:

$$
M_{i}=S\left(M_{i}, F_{i}\right)
$$


where $M_{i}$ indicate the $i^{\text {th }}$ moth, $F_{i}$ indicates the $j^{\text {th }}$ moth of the spiral function $S$. Here, the motion of moth is $n$ logarithmic spiral whose starting point should be the moth, the final point should be flame and a range does not surpass the exploration area. So, the point of the MFO approach in logarithmic scale given as:

$$
S\left(M_{i}, F_{i}\right)=D_{i} \cdot e^{b t} \cdot \cos (2 \pi t)+F_{j}
$$

where $D_{i}$ is the remoteness of $i^{\text {th }}$ moth from $j^{\text {th }}$ flame. " $b$ " is the constant indicating the profile of the log spiral and $t$ is the random number in the range of $[-1,1]$. The calculation of distance $D_{i}$ can be given as:

$$
D_{i}=\left|F_{j}-M_{i}\right|
$$

where $D_{i}$ is the remoteness of $i^{\text {th }}$ moth from the $j^{\text {th }}$ moth, $F_{j}$ shows the $j^{\text {th }}$ flame and $M_{i}$ shows the $i^{\text {th }}$ moth. d. Adaptive nature of reducing the number of flames

Further, the numbers of flames are reduced while the number of iterations is increasing which is given by:

$$
\text { Number of flames }=\operatorname{round}\left(N-I * \frac{N-1}{T}\right)
$$

\subsection{Formulation of multi-objective function with the non-sorting MFO algorithm}

The multi-objective optimization issues comprising the amount of clashing objective functions are optimized simultaneously while at the same time fulfilling all the constraints. There are the number of optimization methods that are utilized prior to the article to explain the multi-objective OPF problem. Starting with those works of literature, it is seen that numerous researchers have changed over that multi-objective issue under a single objective issue utilizing the straight mixture of the two clashing objective works toward applying the weighting components approach. Furthermore, the finer route for finding the result of the multi-objective issue may be to estimate the set of ideal tradeoffs what's more discovering the best compromising solutions around every last one of pareto fronts. The multi-objective optimization problem needs to be figured as:

$$
\begin{aligned}
& \operatorname{Min}_{i}(u), \quad i=1,2,3 \ldots \ldots \ldots \ldots, N \\
& \text { ubjected to } g_{j}(u)=0, \quad j=1,2,3 \ldots \ldots \ldots . M \\
& h_{k}(u) \leq 0, \quad k=1,2,3 \ldots \ldots \ldots \ldots .
\end{aligned}
$$

where $f_{i}$ shows the $i^{\text {th }}$ objective function; $u$ represents the decision vectors; $N$ stands for total objective function; $M$ stands for the total power flow bounds and $K$ stands for total physical bounds on devices. In the multi-objective optimization, the non-dominated sorting technique can have two probabilities, one dominating the other objectives or no one dominated the other. In other words, without losing generality; $u_{1}$ dominates the $u_{2}$ only if the given two criteria are fulfilled:

$$
\begin{array}{ll}
\forall i \in\{1,2,3 \ldots \ldots N\} & : f_{i}\left(u_{1}\right) \leq f_{i}\left(u_{2}\right) \\
\exists j \in\{1,2,3 \ldots \ldots N\} & : f_{j}\left(u_{1}\right) \leq f_{j}\left(u_{2}\right)
\end{array}
$$

In the event that any of the above conditions is disregarded, at that point, arrangement $u_{1}$ does not rule $u_{2}$. The arrangement $u_{1}$ is known as the non-commanded arrangement, if $u_{1}$ overwhelms the $u_{2}$ arrangements. Flowchart of given MFO approach for resolving OPF issue is shown in Figure 4.

The method of the suggested non-sorting MFO approach has appeared in algorithm-1. Initially, introduce parameters, for example, population size $N_{\text {pop }}$, and stopping value, here it is the most extreme no. of generation to proceeds the method. Besides, a random parent population $P_{o}$ in possible space $\mathrm{S}$ is produced and every objective function of the objective vector $\mathrm{F}$ for $P_{o}$ is assessed. Afterward, non-dominated sorting along with crowding distance calculation as clarified in table [25] and is implemented on $P_{o}$. Subsequently, the MFO approach is utilized to make the fresh population $P_{j}$, and then it is converged with $P_{o}$ to shape the blended population $P_{i}$. This $P_{i}$ is arranged in view of elitism non-domination, and in light of the figured estimations of crowding distance (CD) and non-domination rank (NDR), the best $N_{\text {pop }}$ arrangements are refreshed to frame another parent population. This procedure is repeated until the highest no. of generations (cycles) are come to. It must be noticed that a similar approach can be utilized along with end criteria set according to the total evaluations of the function.

Algorithm 1. Non-dominated moth flame optimization [25] 
Step 1: Create population $P_{o}$ randomly in the set of solution $\mathrm{S}$ and objective function vector $\mathrm{F}$ for the created $P_{o}$.

Step 2: Sort the $P_{o}$ in light of the elitist non dominated sort strategy and discover the non-domination rank (NDR) and pareto fronts.

Step 3: For each pareto front, find the crowding distance (CD).

Step 4: Now using MFO algorithm, modernize solutions $P_{j}$.

Step 5: To create $P_{i}=P_{o} \cup P_{j}$, combine $P_{o}$ and $P_{j}$.

Step 6: For $P_{i}$ accomplish step 2 according to NDR and CD sort $P_{i}$.

Step 7: For first $N_{\text {pop }}$ members of $P_{i}$, Substitute $P_{o}$ with $P_{i}$.

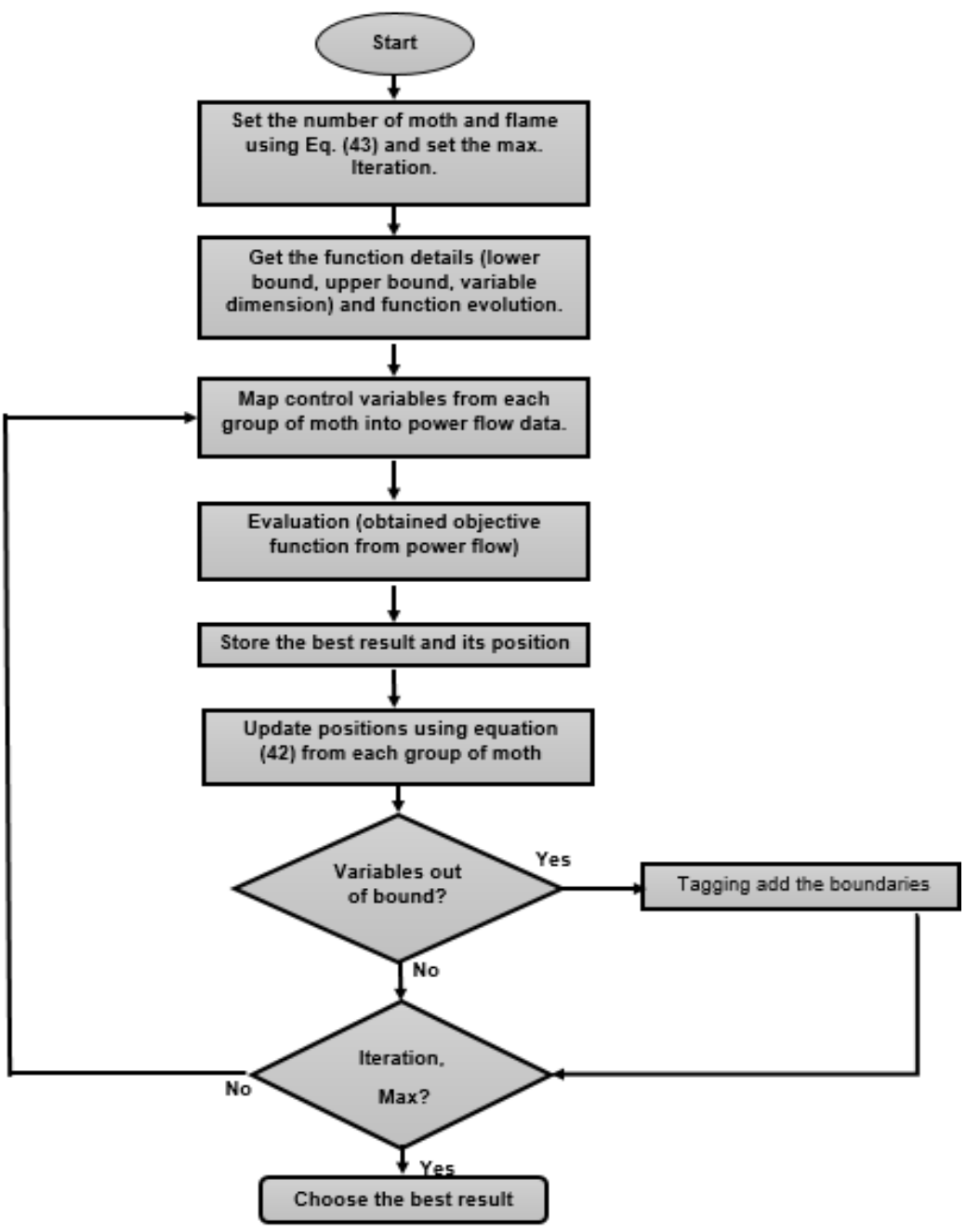

Figure 4. Flowchart of proposed MFO for solving OPF

\subsection{Fuzzy model for the multi-objective problem}

For finding the best compromising solution among all the non-inferior results, the fuzzy membership approach can be applied in multi-objective functions. The fuzzy membership function $\mu_{f_{i}}$ is looking after minimum $f_{i}^{\text {min }}$ and maximum $f_{i}^{\text {max }}$ values for every objective goal with the help of fuzzy membership function. Now, the membership function of $i^{\text {th }}$ objective is expressed as:

$$
\mu_{f_{i}}= \begin{cases}1 & f_{i} \leq f_{i}^{\text {min }} \\ \frac{f_{i}^{\text {max }}-f_{i}}{f_{i}^{\text {max }}-f_{i}^{\text {min }}} & f_{i}^{\text {min }}<f_{i}<f_{i}^{\text {max }} \\ 0 & f_{i} \geq f_{i}^{\text {max }}\end{cases}
$$


The values of membership functions lie in the scale of (0-1) and shows that how much it satisfies the function $f_{i}$. Afterward, the decision-making function $\mu^{k}$ should be computed as:

$$
\mu^{k}=\frac{\sum_{i=1}^{N} \mu_{f_{i}}^{k}}{\sum_{k=1}^{M} \sum_{i=1}^{N} \mu_{f_{i}}^{k}}
$$

the decision-making function can also be considered as the normalized membership function for non-inferior results and shows the ranking of the non-dominated results. The final result is treated as the best compromising solution among all the pareto front having the value maximum $\left\{\mu^{k}: k=1,2,3 \ldots \ldots . M\right\}$.

\section{SIMULATION RESULTS AND ANALYSIS}

In this analysis, the single objective and multi-objective optimization using MFO algorithm are implemented to solve the stochastic OPF problem with wind and solar power plants. The adapted IEEE-30 bus framework with wind and solar PV plants can be utilized to show the adequacy of the suggested approach. The line information, load information and the data of wind and solar power plants are directly taken from [23]. The primary qualities of adapted IEEE-30 bus framework are given in Table 1 . There are basically two cases each having two scenarios as given below;

Part-A optimal power flow with two winds and one solar power plants.

Here, total 10 dissimilar test cases are considered as presented in Table 4. Outcomes of the case studies considering moth flame approach are tabularized and described in this section. The first six case studies are for single objectives optimization and rest of the cases are multi-objective optimization problems incorporated with solar and wind power plants. In proposed work, the programming is done with MATLAB programming language and calculated on the system having $3.4 \mathrm{GHz}$ Intel i5 processor with 8 GB RAM. Here, the search agent value is choosing to be 40 and each algorithm is analyzed for 10 independent runs with 500 iterations per run.

Table 4. Summary of case studies for adapted IEEE-30 bus test system

\begin{tabular}{lll}
\hline Test system & Case \# & \multicolumn{1}{c}{ Single and multi-objectives functions } \\
\hline & Case \# 1 & Minimization total fuel cost. \\
& Case \# 2 & Emission minimization. \\
& Case \# 3 & Voltage deviation minimization. \\
IEEE & Case \# 4 & Active power loss minimization. \\
30-bus test & Case \# 5 & Voltage stability enhancement. \\
system & Case \# 6 & Total Fuel Cost with carbon Tax minimization. \\
(modified) & Case \# 7 & Total Fuel Cost and Emission minimization. \\
& Case \# 8 & Total Fuel Cost, Emission, and active power loss minimization. \\
& Case \# 9 & Total Fuel Cost, Emission, and voltage deviation minimization. \\
& Case \# 10 & Total Fuel Cost, Emission, Voltage deviation and active power loss minimization. \\
\hline
\end{tabular}

\subsection{Scenario-1 (single objective OPF with wind and solar PV plants)}

Here all the objective goals specified in mathematical formulation and are solved as solo objective optimization issue with the help of a moth flame optimization approach. The limits of all control variables like, voltage magnitudes of all the generators and transformer tap settings are lies in a span of [0.9-1.1] p.u. The upper and lower voltage span of all PQ buses taken between [0.95-1.1] p.u, and the reactive power compensator having the rating between 0 to $5 \mathrm{MVAr}$. The best minimum values of the objective functions starting from case- 1 to case- 6 with control variables are tabulated in Table 5.

The overall fuel cost including the renewable solar and wind power plants cost in case- 1 is $780.485 \$ / \mathrm{hr}$ which is reduced up to $2.018 \$ / \mathrm{hr}$ in comparison with [23] which is tabulated in Table 6 . The convergence curve of case- 1 is displayed in Figure 5 (a). The pollutant gas emission in case-2 is $0.092 \mathrm{Ton} / \mathrm{hr}$. Similarly, the voltage deviation of each bus from the 1.0 per unit is also a significant aspect for a reliable operation of the grid. So, in a case-3, the minimum voltage variation is 0.298 p.u. The active power loss of different transmission lines in case-4 is $1.735 \mathrm{MW}$.

The voltage stability index, also known as $L_{\max }$ index fluctuates from 0 (no load) to 1 (voltage collapse). So, the minimum value for the $L_{\max }$ index in case- 5 is 0.134 . In case- 6 , the carbon tax rate $C_{\text {tax }}$ is taken as $20 \$$ /Tonne [23]. The simulation result of total cost with emission is $809.969 \$ / \mathrm{hr}$ which is less compared to reference [23] shown in Table 6. After comparing the simulation outcomes, it is seen that the proposed method of moth flame optimization technique gives the better results as shown in Figure 5 (b). 
Table 5. Single objectives simulation results obtained for the system under study (Part-A)

\begin{tabular}{|c|c|c|c|c|c|c|c|c|}
\hline Control variables & Max & Min & Case-1 & Case-2 & Case-3 & Case-4 & Case-5 & Case-6 \\
\hline $\mathrm{P}_{\mathrm{G} 2(\text { Thermal) }}$ & 80.00 & 20.00 & 27.516 & 46.634 & 80.000 & 60.741 & 20.000 & 33.275 \\
\hline $\mathrm{P}_{\mathrm{G} 8(\text { Thermal) }}$ & 35.00 & 10.00 & 10.000 & 35.000 & 35.000 & 35.000 & 35.000 & 10.000 \\
\hline $\mathrm{P}_{\mathrm{G} 5 \text { (Wind) }}$ & 75.00 & 0.00 & 43.868 & 75.000 & 75.000 & 75.000 & 65.311 & 45.974 \\
\hline $\mathrm{P}_{\mathrm{G} 11 \text { (Wind) }}$ & 60.00 & 0.00 & 37.140 & 53.681 & 2.010 & 60.000 & 60.000 & 38.793 \\
\hline $\mathrm{P}_{\mathrm{G} 13 \text { (Solar) }}$ & 50.00 & 0.00 & 35.431 & 44.183 & 0.000 & 46.439 & 25.271 & 36.715 \\
\hline $\mathrm{V}_{\mathrm{G} 1}$ & 1.10 & 0.95 & 1.100 & 0.950 & 0.950 & 1.100 & 0.950 & 1.100 \\
\hline $\mathrm{V}_{\mathrm{G} 2}$ & 1.10 & 0.95 & 1.089 & 0.974 & 0.950 & 1.100 & 1.100 & 1.090 \\
\hline $\mathrm{V}_{\mathrm{G} 5}$ & 1.10 & 0.95 & 1.070 & 1.036 & 0.999 & 1.091 & 1.100 & 1.071 \\
\hline $\mathrm{V}_{\mathrm{G} 8}$ & 1.10 & 0.95 & 1.100 & 1.100 & 1.094 & 1.100 & 1.100 & 1.100 \\
\hline $\mathrm{V}_{\mathrm{G} 11}$ & 1.10 & 0.95 & 1.100 & 1.100 & 1.100 & 1.100 & 1.100 & 1.100 \\
\hline $\mathrm{V}_{\mathrm{G} 13}$ & 1.10 & 0.95 & 1.094 & 1.100 & 1.056 & 1.100 & 1.100 & 1.095 \\
\hline $\mathrm{QC}_{10}$ & 5.00 & 0.00 & 4.985 & 5.000 & 5.000 & 1.426 & 5.000 & 5.000 \\
\hline $\mathrm{QC}_{12}$ & 5.00 & 0.00 & 5.000 & 0.000 & 0.000 & 5.000 & 4.030 & 5.000 \\
\hline $\mathrm{QC}_{15}$ & 5.00 & 0.00 & 0.000 & 5.000 & 4.850 & 4.933 & 5.000 & 0.000 \\
\hline $\mathrm{QC}_{17}$ & 5.00 & 0.00 & 0.000 & 3.723 & 0.052 & 0.000 & 5.000 & 4.757 \\
\hline $\mathrm{QC}_{20}$ & 5.00 & 0.00 & 5.000 & 5.000 & 5.000 & 5.000 & 5.000 & 0.000 \\
\hline $\mathrm{QC}_{21}$ & 5.00 & 0.00 & 0.013 & 5.000 & 5.000 & 0.046 & 4.959 & 5.000 \\
\hline $\mathrm{QC}_{23}$ & 5.00 & 0.00 & 0.004 & 5.000 & 1.019 & 5.000 & 5.000 & 5.000 \\
\hline $\mathrm{QC}_{24}$ & 5.00 & 0.00 & 0.083 & 2.057 & 5.000 & 0.006 & 0.000 & 0.000 \\
\hline $\mathrm{QC}_{29}$ & 5.00 & 0.00 & 5.000 & 5.000 & 5.000 & 4.990 & 5.000 & 5.000 \\
\hline $\mathrm{T}_{11(6-9)}$ & 1.10 & 0.9 & 0.900 & 1.086 & 1.100 & 1.100 & 0.900 & 0.900 \\
\hline $\mathrm{T}_{12(6-10)}$ & 1.10 & 0.9 & 0.922 & 0.916 & 1.100 & 0.900 & 1.019 & 0.900 \\
\hline $\mathrm{T}_{15(4-12)}$ & 1.10 & 0.9 & 1.099 & 0.900 & 0.900 & 0.916 & 1.100 & 1.100 \\
\hline $\mathrm{T}_{36(28-27)}$ & 1.10 & 0.9 & 1.100 & 1.100 & 1.100 & 1.066 & 1.100 & 1.100 \\
\hline Total F.C (\$/h) & - & - & 780.485 & 914.017 & 1013.712 & 957.229 & 919.634 & \\
\hline Emission $(\mathrm{T} / \mathrm{h})$ & - & - & 1.762 & 0.092 & 0.358 & 0.100 & 0.264 & $0 . \overline{8} 98$ \\
\hline V.D (p.u) & - & - & 1.046 & 0.410 & 0.298 & 1.342 & 1.379 & 1.067 \\
\hline Ploss(MW) & - & - & 5.464 & 3.752 & 14.581 & 1.735 & 3.062 & 5.010 \\
\hline Lmax & - & - & - & - & - & - & 0.134 & \\
\hline $\begin{array}{l}\text { Total F.C with a carbon } \\
\operatorname{tax}(\$ / h)\end{array}$ & - & - & - & - & - & - & - & 809.969 \\
\hline
\end{tabular}

Table 6. Comparison of the simulation results for single objectives (Part-A)

\begin{tabular}{lcc}
\hline Single objectives functions & Proposed MFO & SHADE [23] \\
\hline Total F.C $(\$ / \mathrm{h})$ & 780.485 & 782.503 \\
Emission $(\mathrm{T} / \mathrm{h})$ & 0.092 & NA \\
V.D $($ p.u $)$ & 0.298 & NA \\
Ploss $(\mathrm{MW})$ & 1.735 & NA \\
Lmax & 0.134 & NA \\
Total F.C with a carbon tax $(\$ / \mathrm{h})$ & 809.969 & 810.346 \\
\hline
\end{tabular}

\subsection{Scenario-2 (Multi-objective OPF with wind and solar PV plants)}

In this scenario, two objectives, three objectives and four objectives optimized simultaneously with the moth flame optimization approach. In the multi-objective optimization, the non-dominated sorting optimization technique is applied for finding the archives of different objectives simultaneously. Here, 30 non-dominates solutions are maintained for finding the pareto front for IEEE 30-bus framework. The case-7 to case-10 are treated as the multi-objective optimization problems for IEEE 30-bus framework with wind and solar plants. For finding the best compromising solution among all the pareto archives, the fuzzy decision-making approach is employed. The finest compromising solutions for the different cases are demonstrated in boldfaced and mentioned in Table 7 . The finest compromise solutions are obtained using the moth flame optimization techniques with the case-7 is displayed in Figure 5 (b). The pareto front of case- 8 and case-9 are displayed in Figure 6 (a) and Figure 6 (b). It is come to know that the MOMFO approach is one of the best approaches for searching the optimal solutions of the multi-objective OPF issue integrating solar and wind plants. Part-B optimal power flow with three winds power plants. Here, the solar power plant at bus number-13 is replaced with another wind farm to check the techno-economic impact on optimal power flow issue. The parameters of are given into the Table 3 . There are also the similar cases of single and multi-objective optimization are taken. The control variables and maximum and minimum limits are same as Part-A.

\subsection{Scenario-3 (single objective OPF with three wind power plants)}

Here the all objectives are treated as the single objectives and optimized with the help of moth flame optimization algorithm. The best optimized results are tabulated in Table 8. For Case-1, the total fuel cost including three renewable wind power plants as in case-1 is $794.107 \$ / \mathrm{hr}$ which is increased up to $13.622 \$ / \mathrm{hr}$ in comparison with fuel cost of part-A which is tabulated in Table 6 . The convergence curve of total fuel cost is displayed in 
Figure 7. The pollutant gas emission in case- 2 is $0.092 \mathrm{Ton} / \mathrm{hr}$, which similar as emission in Part-A. Likewise, the voltage deviation of each bus that is case-3, the minimum value is 0.284 p.u which reduced up to 0.014 p.u in comparison with the Part-A. The active power loss of different transmission lines in case- 4 is $1.735 \mathrm{MW}$. The voltage stability index, also known as $L_{\max }$ index fluctuates from 0 (no load) to 1 (voltage collapse). So, the minimum value for the $L_{\text {max }}$ index in case- 5 is 0.134 . In case- 6 , the carbon tax rate $C_{\text {tax }}$ is taken as 20 \$/Tonne. The simulation result of total cost with emission $823.631 \mathrm{\$} / \mathrm{hr}$ which is $13.661 \mathrm{\$} / \mathrm{hr}$ less in comparison with Part-A. After comparing the simulation outcomes, it shows that the proposed MFO algorithm is well applied for the OPF Problem with the wind power plants. But in comparison with the Part-A, the fuel cost is somewhat more.

\subsection{Scenario-4 (multi-objective OPF with three wind plants)}

As same way as Part-A, multi-objective optimization problems that is two objectives, three objectives and four objectives with case-7 to case-10 optimized simultaneously with the proposed MFO approach. With fuzzy decision technique, the tradeoff of best compromise solution is shown in Table 9. The results of multi-objective case-7 and case- 8 are portrayed in Figure 8 (a) and Figure (b). So finally, it analyzed that the MOMFO approach is one of the techniques for searching the optimal solutions of the multi-objective $\mathrm{OPF}$ issue integrating wind power plants. But optimized results show the better results in Part-A, as compared with Part-B.

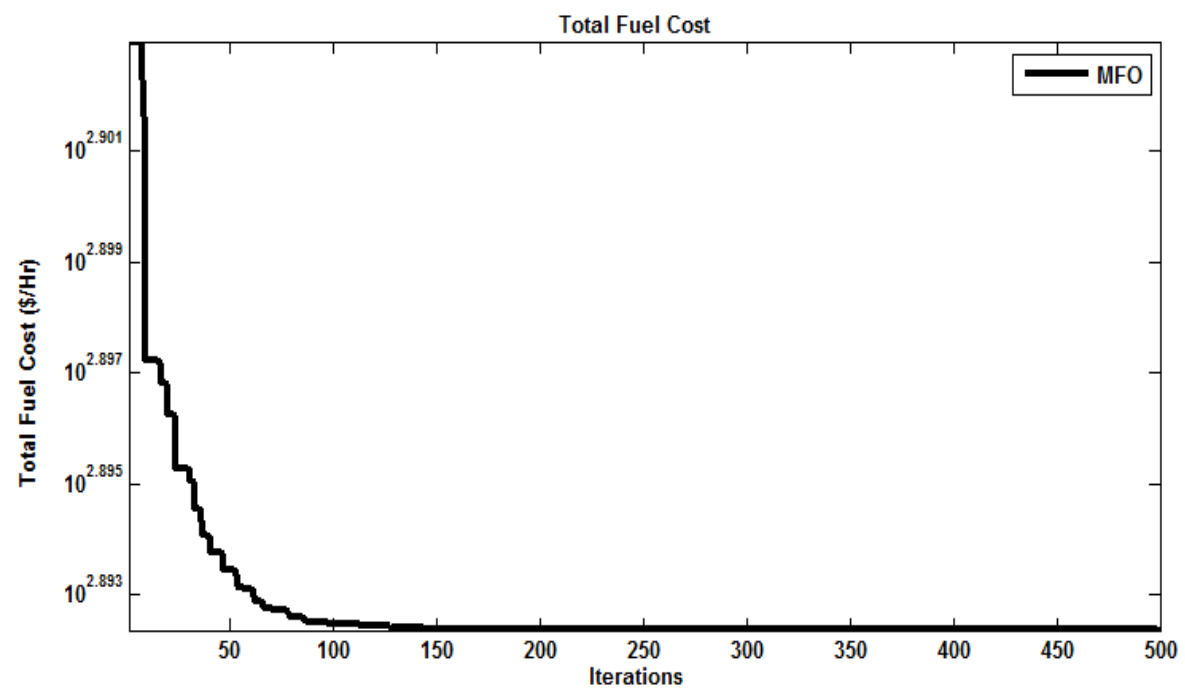

(a)

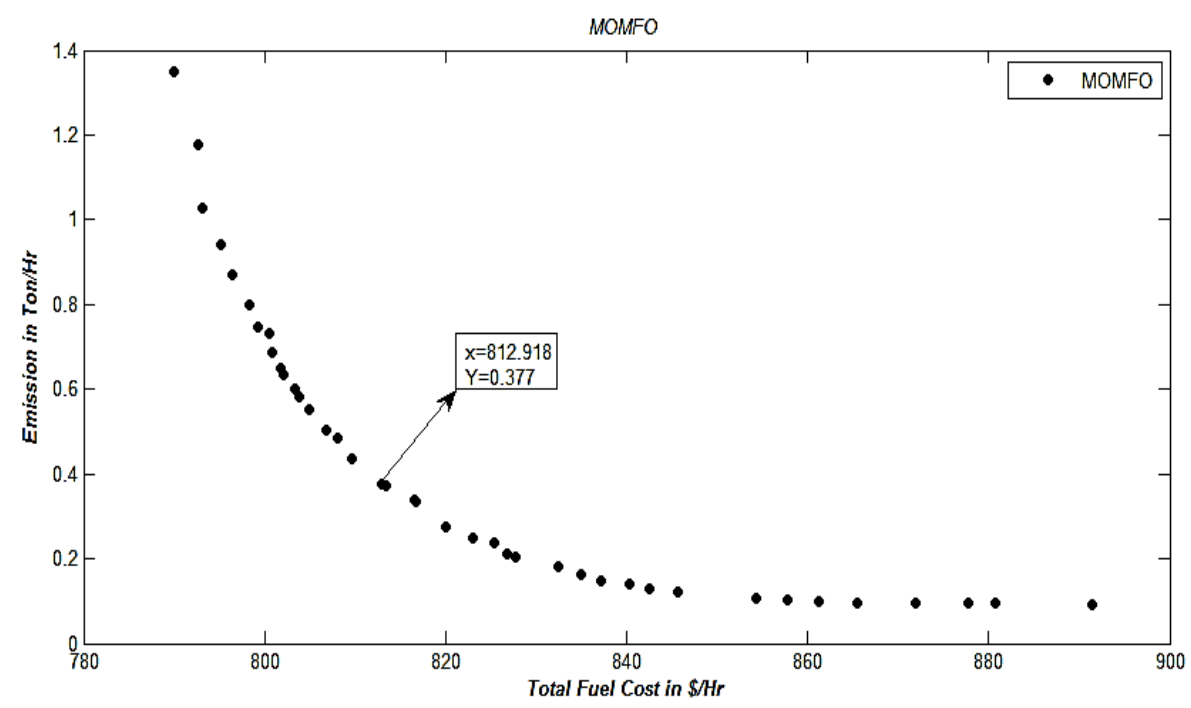

(b)

Figure 5. Convergence characteristics;

(a) total fuel cost minimization (Part-a), (b) total fuel cost and emission minimization (Part-a) 
Table 7. Multi-objectives simulation results obtained for the system under study (Part-A)

\begin{tabular}{|c|c|c|c|c|c|c|}
\hline Control variables & Max & Min & Case-7 & Case- 8 & Case-9 & Case-10 \\
\hline $\mathrm{P}_{\mathrm{G} 2 \text { (Thermal) }}$ & 80.00 & 20.00 & 42.056 & 37.736 & 45.726 & 45.712 \\
\hline $\mathrm{P}_{\mathrm{G} 8(\text { Thermal) }}$ & 35.00 & 10.00 & 12.170 & 11.792 & 30.527 & 15.540 \\
\hline $\mathrm{P}_{\mathrm{G} 5 \text { (Wind) }}$ & 75.00 & 0.00 & 48.909 & 47.306 & 55.820 & 64.067 \\
\hline $\mathrm{P}_{\mathrm{G} 11 \text { (Wind) }}$ & 60.00 & 0.00 & 40.741 & 42.904 & 41.236 & 33.057 \\
\hline $\mathrm{P}_{\mathrm{G} 13 \text { (Solar) }}$ & 50.00 & 0.00 & 37.079 & 38.202 & 43.891 & 44.377 \\
\hline $\mathrm{V}_{\mathrm{G} 1}$ & 1.10 & 0.95 & 1.054 & 1.051 & 1.080 & 1.020 \\
\hline $\mathrm{V}_{\mathrm{G} 2}$ & 1.10 & 0.95 & 1.036 & 1.030 & 1.021 & 0.981 \\
\hline $\mathrm{V}_{\mathrm{G} 5}$ & 1.10 & 0.95 & 1.034 & 1.040 & 1.080 & 1.034 \\
\hline $\mathrm{V}_{\mathrm{G} 8}$ & 1.10 & 0.95 & 1.062 & 1.025 & 1.065 & 1.035 \\
\hline $\mathrm{V}_{\mathrm{G} 11}$ & 1.10 & 0.95 & 1.041 & 1.050 & 1.052 & 1.057 \\
\hline $\mathrm{V}_{\mathrm{G} 13}$ & 1.10 & 0.95 & 1.035 & 1.059 & 1.065 & 1.066 \\
\hline $\mathrm{QC}_{10}$ & 5.00 & 0.00 & 1.618 & 1.472 & 2.906 & 2.111 \\
\hline $\mathrm{QC}_{12}$ & 5.00 & 0.00 & 3.567 & 3.699 & 3.974 & 2.808 \\
\hline $\mathrm{QC}_{15}$ & 5.00 & 0.00 & 3.195 & 2.495 & 3.006 & 2.404 \\
\hline $\mathrm{QC}_{17}$ & 5.00 & 0.00 & 2.561 & 3.637 & 3.273 & 2.829 \\
\hline $\mathrm{QC}_{20}$ & 5.00 & 0.00 & 2.216 & 2.108 & 2.615 & 2.840 \\
\hline $\mathrm{QC}_{21}$ & 5.00 & 0.00 & 3.041 & 3.320 & 2.108 & 1.159 \\
\hline $\mathrm{QC}_{23}$ & 5.00 & 0.00 & 2.912 & 1.562 & 3.148 & 3.585 \\
\hline $\mathrm{QC}_{24}$ & 5.00 & 0.00 & 2.517 & 2.738 & 3.003 & 4.615 \\
\hline $\mathrm{QC}_{29}$ & 5.00 & 0.00 & 2.684 & 2.189 & 2.406 & 3.214 \\
\hline $\mathrm{T}_{11(6-9)}$ & 1.10 & 0.9 & 1.050 & 1.015 & 1.023 & 1.021 \\
\hline $\mathrm{T}_{12(6-10)}$ & 1.10 & 0.9 & 1.000 & 1.001 & 1.040 & 1.036 \\
\hline $\mathrm{T}_{15(4-12)}$ & 1.10 & 0.9 & 0.973 & 0.981 & 1.054 & 0.991 \\
\hline $\mathrm{T}_{36(28-27)}$ & 1.10 & 0.9 & 0.997 & 1.018 & 1.089 & 1.020 \\
\hline Total F.C (\$/h) & - & - & 812.918 & 810.415 & 848.725 & 841.235 \\
\hline Emission $(\mathrm{T} / \mathrm{h})$ & - & - & 0.377 & 0.440 & 0.115 & 0.161 \\
\hline V.D (p.u) & - & - & 0.952 & 0.491 & 0.940 & 0.682 \\
\hline Ploss (MW) & - & - & 4.614 & 4.211 & 3.293 & 4.137 \\
\hline
\end{tabular}

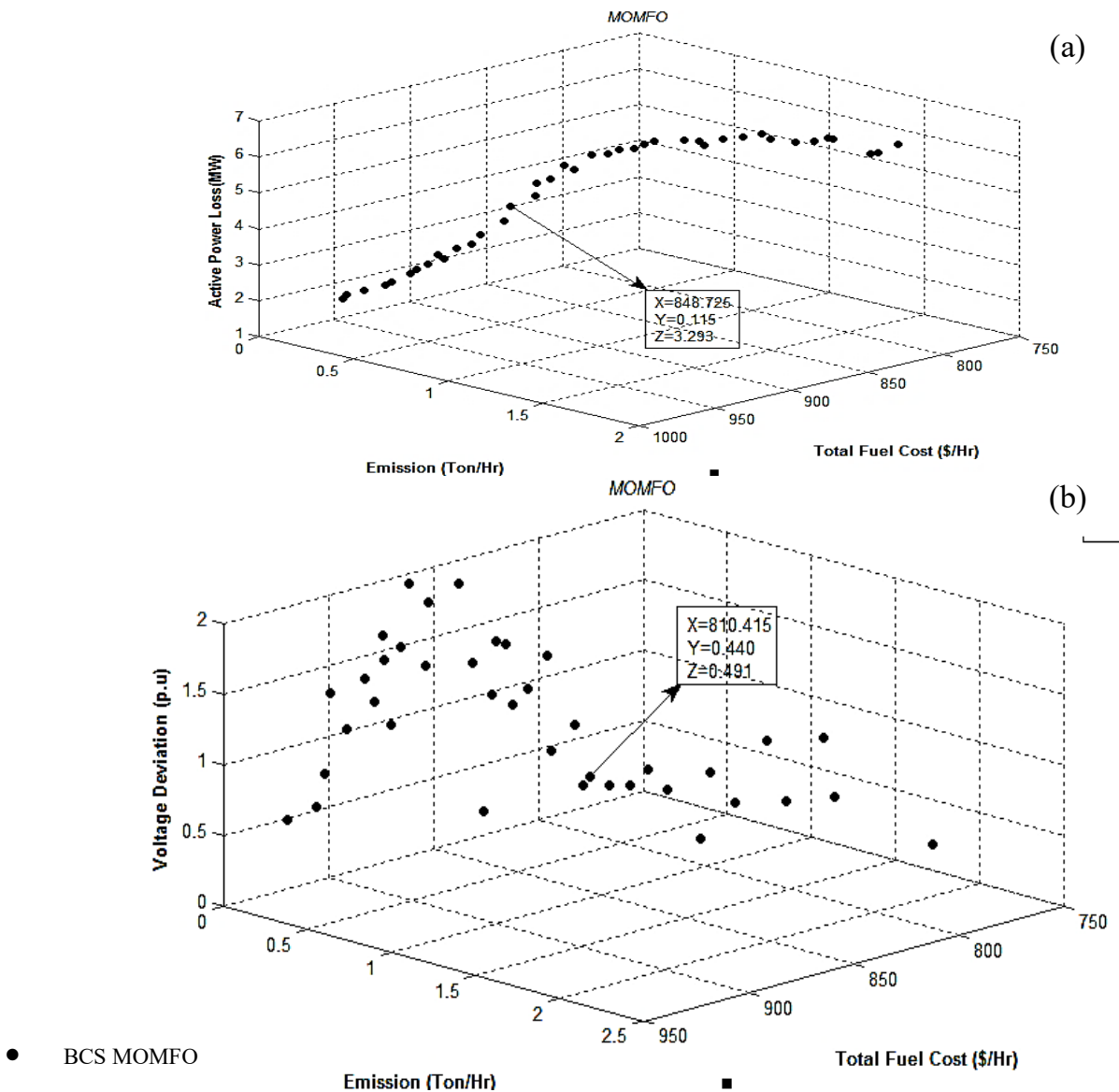

Figure 6. Convergence characteristics; (a) total fuel cost, Emission, and active loss minimization (Part-A), (b) total fuel cost, Emission and voltage deviation minimization (Part-A) 
Table 8 Single objectives simulation results obtained for three wind power plants (Part-B)

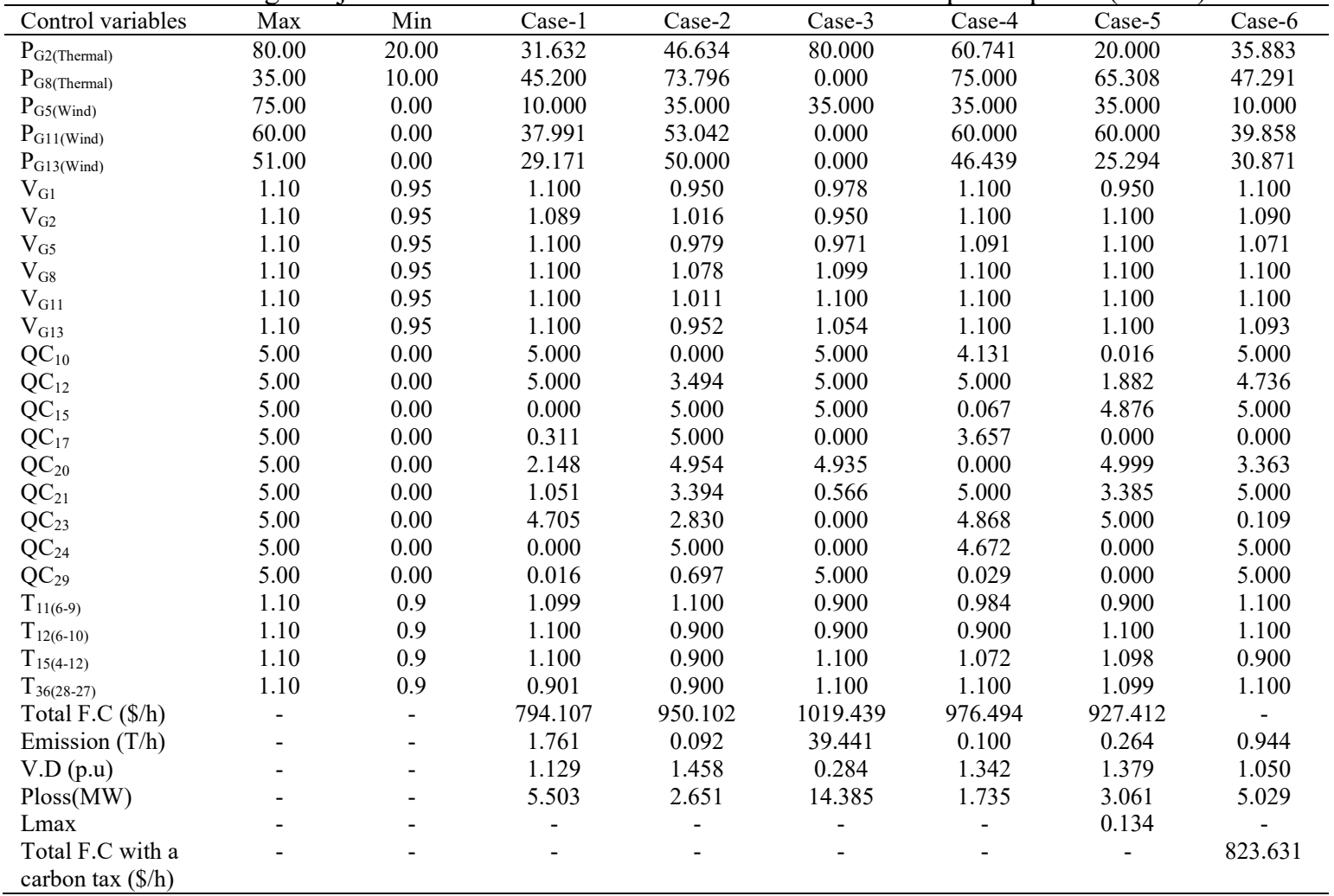

Table 9. Multi-objectives simulation results obtained for three wind power plants (Part-B)

\begin{tabular}{|c|c|c|c|c|c|c|}
\hline Control variables & Max & Min & Case-7 & Case- 8 & Case-9 & Case- 10 \\
\hline $\mathrm{P}_{\mathrm{G} 2 \text { (Thermal) }}$ & 80.00 & 20.00 & 42.635 & 42.212 & 41.838 & 50.072 \\
\hline $\mathrm{P}_{\mathrm{G} 8(\text { Thermal) }}$ & 35.00 & 10.00 & 50.239 & 44.141 & 61.953 & 52.700 \\
\hline $\mathrm{P}_{\mathrm{G} 5 \text { (Wind) }}$ & 75.00 & 0.00 & 11.218 & 12.521 & 21.691 & 26.677 \\
\hline $\mathrm{P}_{\mathrm{G} 13 \text { (Wind) }}$ & 51.00 & 0.00 & 29.884 & 31.836 & 34.475 & 32.635 \\
\hline $\mathrm{V}_{\mathrm{G} 1}$ & 1.10 & 0.95 & 1.020 & 1.046 & 1.089 & 1.056 \\
\hline $\mathrm{V}_{\mathrm{G} 2}$ & 1.10 & 0.95 & 1.000 & 1.058 & 1.080 & 0.982 \\
\hline $\mathrm{V}_{\mathrm{G} 11}$ & 1.10 & 0.95 & 1.060 & 1.037 & 1.074 & 1.071 \\
\hline $\mathrm{V}_{\mathrm{G} 13}$ & 1.10 & 0.95 & 1.018 & 1.045 & 1.067 & 0.995 \\
\hline $\mathrm{QC}_{10}$ & 5.00 & 0.00 & 2.268 & 3.304 & 4.339 & 2.746 \\
\hline $\mathrm{QC}_{12}$ & 5.00 & 0.00 & 1.489 & 1.750 & 2.508 & 3.670 \\
\hline $\mathrm{QC}_{15}$ & 5.00 & 0.00 & 2.413 & 3.324 & 3.033 & 3.709 \\
\hline $\mathrm{QC}_{24}$ & 5.00 & 0.00 & 2.684 & 3.305 & 2.756 & 3.737 \\
\hline $\mathrm{QC}_{29}$ & 5.00 & 0.00 & 1.412 & 2.521 & 4.425 & 1.607 \\
\hline $\mathrm{T}_{11(6-9)}$ & 1.10 & 0.9 & 0.990 & 0.934 & 1.020 & 0.964 \\
\hline $\mathrm{T}_{12(6-10)}$ & 1.10 & 0.9 & 0.998 & 1.012 & 1.056 & 0.994 \\
\hline $\mathrm{T}_{15(4-12)}$ & 1.10 & 0.9 & 0.982 & 0.999 & 1.004 & 1.046 \\
\hline $\mathrm{T}_{36(28-27)}$ & 1.10 & 0.9 & 1.039 & 1.037 & 1.012 & 0.913 \\
\hline Total F.C (\$/h) & - & - & 822.786 & 809.484 & 853.417 & 854.093 \\
\hline Emission $(\mathrm{T} / \mathrm{h})$ & - & - & 0.473 & 1.046 & 0.151 & 0.154 \\
\hline V.D (p.u) & - & - & 0.823 & 0.481 & 0.698 & 0.701 \\
\hline Ploss (MW) & - & - & 0.823 & 3.594 & 3.307 & 4.072 \\
\hline
\end{tabular}




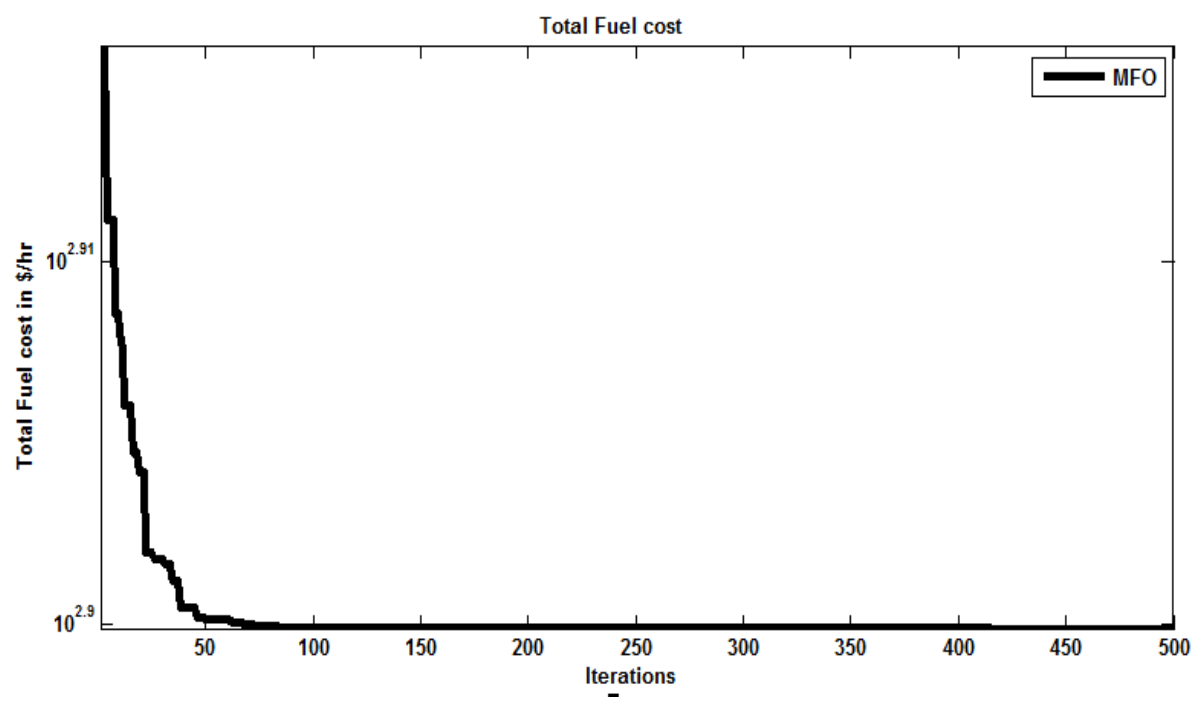

Figure 7. Convergence characteristics of total fuel cost minimization with three wind power plants (Part-B)

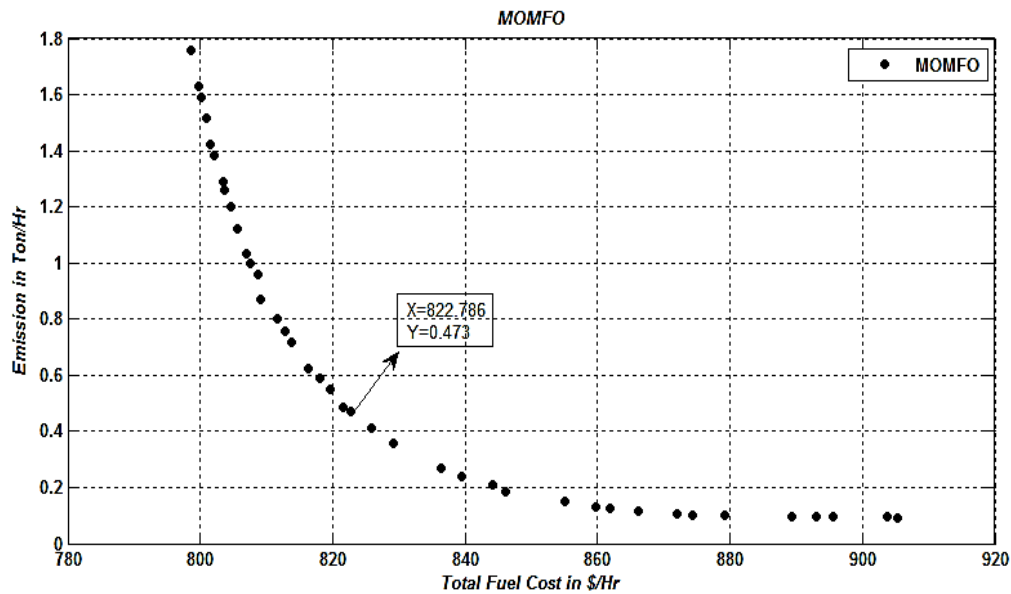

(a)

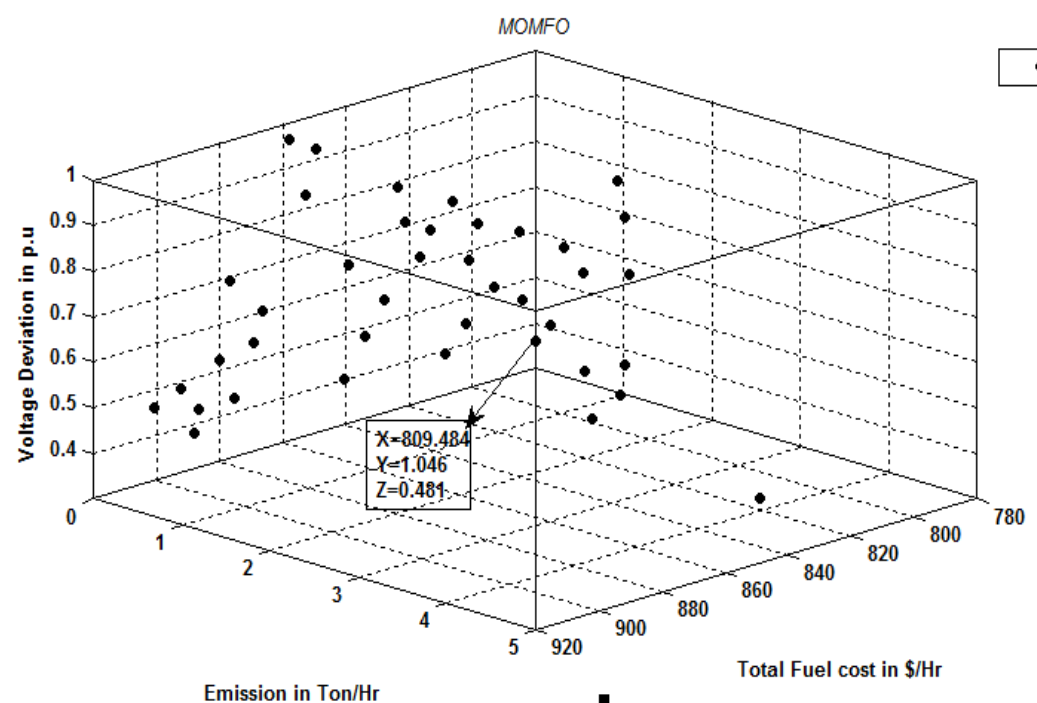

(b)

Figure 8. Convergence characteristics; (a) total fuel cost and emission minimization with three wind power plants (Part-B), (b) total fuel cost, Emission and voltage deviation minimization with three wind power plants (Part-B) 


\section{CONCLUSION}

This paper proposed the solution technique to single and multi-objective optimal power flow (MOOPF) issue containing thermal power plants plus solar and wind power plants. The paper contains the techno-economic analysis of two parts. The first part contains the two wind and one solar power plants and the analysis of the OPF problem. The performances are compared with recently available optimization technique. From the obtained result, the suggested MOMFO accomplishes improved quality and additionally feasible solutions for each situation of optimal power flow and has better convergence compare to other algorithms. In second part, the solar PV plant is replaced with the wind power plant and the solution of optimal power flow issue. The results are compared with the two different parts. From the techno-economic analysis, the multi-objective OPF problem with the two wind power plants and one solar power plant having less total fuel cost in comparison with the three wind power plants. So finally, it is shown that with a non-dominated sorting method, MOMFO can be proficiently utilized for solving small and large optimal power flow issues by incorporating wind and solar power plants.

\section{REFERENCES}

[1] J. L. Carpentier, "Optimal power flows uses, methods, and developments," IFAC Proc. Vol., vol. 18, no. 7, pp. 11-21, 1985.

[2] K. S. Pandya and S. K. Joshi, “A survey of Optimal Power Flow methods," Journal Appl. Inf. Technolology, vol. 4, no. 5, pp. 450-458, 2005.

[3] D. H. Wolpert and W. G. Macready, "No free lunch theorems for optimization," IEEE Trans. Evol. Comput., vol. 1, no. 1 , pp. 67-82, 1997.

[4] M. M. A. M. Abido, "Optimal power flow using particle swarm optimization," J. Electr. Power Energy Syst., vol. 24, no. 7 , pp. 563-571, 2002.

[5] M. A. Abido, "Optimal power flow using tabu search algorithm," Electr. Power Components System, vol. 30, no. 5, pp. 469-483, 2002.

[6] L. L. Lai, J. T. Ma, R. Yokoyama, and M. Zhao, "Improved genetic algorithms for optimal power flow under both normal and contingent operation states,” Int. J. Electr. Power Energy Syst., vol. 19, no. 5, pp. 287-292, 1997.

[7] H. R. E. H. Bouchekara, A. E. Chaib, M. A. Abido, and R. A. El-Sehiemy, "Optimal power flow using an improved colliding bodies optimization algorithm," Appl. Soft Comput., vol. 42, pp. 119-131, 2016.

[8] H. R. E. H. Bouchekara, "Optimal power flow using black-hole-based optimization approach," Appl. Soft Computing, vol. 24, pp. 879-888, 2014.

[9] A. A. A. Mohamed, Y. S. Mohamed, A. A. M. El-Gaafary, and A. M. Hemeida, "Optimal power flow using moth swarm algorithm," Electr. Power Syst. Res., vol. 142, pp. 190-206, 2017.

[10] S. S. Reddy and C. S. Rathnam, "Optimal power flow using glowworm swarm optimization," Int. J. Electr. Power Energy Syst., vol. 80, pp. 128-139, 2016.

[11] A. E. A. Chaib, H. R. E. H. Bouchekara, R. Mehasni, and M. A. Abido, "Optimal power flow with emission and nonsmooth cost functions using backtracking search optimization algorithm," Int. J. Electr. Power Energy Syst., vol. 81, pp. 64-77, 2016.

[12] H. R. E. H. Bouchekara, A. E. Chaib, M. A. Abido, and R. A. El-Sehiemy, "Optimal power flow using an Improved Colliding Bodies Optimization algorithm,” Appl. Soft Comput., vol. 42, pp. 119-131, 2016.

[13] R. Roy and H. T. Jadhav, "Optimal power flow solution of power system incorporating stochastic wind power using Gbest guided artificial bee colony algorithm," Int J Electr Power Energy Syst, vol. 64, pp. 562-78, 2015.

[14] A. Panda and M. Tripathy, "Optimal power flow solution of wind integrated power system using modified bacteria foraging algorithm," Int. J. Electr. Power Energy Syst., vol. 54, pp. 306-314, 2014.

[15] A. Panda and M. Tripathy, "Security constrained optimal power flow solution of wind-thermal generation system using modified bacteria foraging algorithm," Energy, vol. 93, part 1, pp. 816-827, 2015.

[16] L. Shi, C. Wang, L. Yao, Y. Ni, and M. Bazargan, "Optimal power flow solution incorporating wind power," IEEE Syst. J., vol. 6, no. 2, pp. 233-241, 2012.

[17] R. A. Jabr and B. C. Pal, "Intermittent wind generation in optimal power flow dispatching," IET Gener. Transm. Distrib., vol. 3, no. 1, pp. 66-74, 2009.

[18] S. Mishra, Y. Mishra, and S. Vignesh. "Security constrained economic dispatch considering wind energy conversion systems," Power and Energy Society General Meeting, pp. 1-8, 2011.

[19] Z. Wei, P. Yu, and S. Hui. "Optimal wind-thermal coordination dispatch based on risk reserve constraints." Europ. Transact. Elect. Power, vol. 21, no. 1, pp. 740-756, 2011.

[20] H. M. Dubey, M. Pandit, and B. K. Panigrahi, "Hybrid flower pollination algorithm with time-varying fuzzy selection mechanism for wind integrated multi-objective dynamic economic dispatch," Renewable Energy vol. 83, pp. 188-202, 2015.

[21] H. Tazvinga, B. Zhu, and X. Xia "Optimal power flow management for distributed energy resources with batteries," Energy Convers Manage, vol. 102, pp. 104-110, 2015.

[22] K. Kusakana, "Optimal scheduling for distributed hybrid system with pumped hydro storage." Energy Convers. Manage., vol. 111, pp. 253-260, 2016.

[23] P. P. Biswas, P. N. Suganthan, and G. A. J. Amartunga, "Optimal power flow solutions incorporating stochastic wind and solar," Energy Conversion and Managemant, vol. 148, pp. 1194-1207, 2017.

[24] S. Mirjalili, "Moth-flame optimization algorithm: A novel nature-inspired heuristic paradigm," Knowledge-Based Syst., vol. 89, pp. 228-249, 2015.

[25] V. Savsani and M. A. Tawhid, "Non-dominated sorting moth flame optimization (NS-MFO) for multi-objective problems," Engineering Applications for Artificial Intelligence., vol. 63, pp. 20-32, 2017. 